\title{
Effect of Thyroid on Fatty Acid Biosynthesis in Brain
}

\author{
Jorge Grippo and John H. MenKes ${ }^{[30]}$ \\ Division of Pediatric Neurology, University of California Los Angeles School of Medicine, Los Angeles, California, USA
}

\begin{abstract}
Extract
Triodothyronine $\left(\mathrm{T}_{3}\right)$ was given daily by injection to rats from 1 day of age to $2 \mathrm{hr}$ prior to death. In the brain microsomal fraction of 5- to 6-day-old animals, incorporation of malonyl-CoA into total fatty acids increased from 0.9 to $2.25 \mathrm{~m} \mu \mathrm{moles} / \mathrm{mg}$ protein. Although thyroid increased precursor incorporation into total fatty acids in other age groups, the difference was not statistically significant. Increased precursor incorporation was entirely due to increased formation of saturated fatty acids, and this effect was observed at all age groups.

Incorporation of acetyl-CoA into saturated and unsaturated fatty acids by the mitochondrial fraction was not increased significantly by administration of $T_{3}$.

In rats made hypothyroid at birth, fatty acid chain elongation was reduced in both the microsomal and the mitochondrial fractions. At 6 days of age, incorporation of malonyl-CoA by the microsomal fraction fell from 1.41 to $0.17 \mathrm{~m} \mu$ moles $/ \mathrm{mg}$ protein. These studies suggest that thyroid stimulates the microsomal-fatty acid-brain elongation system involved in the synthesis of saturated fatty acids characteristic of myelin lipids.
\end{abstract}

\section{Speculation}

The stimulation of fatty acid biosynthesis by thyroid hormone is specifically limited to the synthesis of saturated fatty acids by the microsomal fraction. Since the effect of thyroid is probably mediated by enzyme synthesis, we conclude that the microsomal fraction contains two distinct enzyme systems involved in fatty acid chain elongation, one for the formation of polyunsaturated fatty acids, the other for the formation of saturated fatty acids. The activity of the latter system increases at time of myelination, and as a consequence of thyroid stimulation.

\section{Introduction}

Mitochondrial and microsomal fractions of rat brain incorporate acetyl-CoA and malonyl-CoA into a variety of saturated and unsaturated fatty acids [2]. As in liver, fatty acid biosynthesis proceeds by two mechanisms, a de novo process located in the nonparticulate fraction and leading primarily to the formation of palmitic acid, and chain elongation involving the successive addition of 2-carbon units to palmitic acid, the usual primary fatty acid [6]. Two chain elongation systems have been recognized. The mitochondrial system utilizes either acetyl-CoA or malonyl-CoA as substrates and requires reduced nicotinamide adenine dinucleotide (NADH) as hydrogen donor. The microsomal system requires malonyl-CoA as substrate and either NADH or nicotinamide adenine dinucleotide phosphate (NADPH) as hydrogen donor.

In the developing rat brain, total fatty acid biosynthesis is maximal at 15-16 days of age, a time of rapid myelination for this species [1]. Fatty acid chain elon- 
gation by brain microsomal fractions follows a similar developmental pattern, with the peak incorporation of malonyl-CoA into fatty acids occurring at 15 days of age. Analysis of the fatty acids synthesized by microsomes of animals at that age reveals that predominantly saturated fatty acids are formed, in contrast to the preferential incorporation of malonyl-CoA into polyunsaturated fatty acids by the microsomal fractions of liver, adult brain, or brain taken from animals prior to the onset of myelination. By contrast, fatty acid synthesis by the mitochondrial fraction, which yields saturated as well as unsaturated fatty acids, undergoes little qualitative or quantitative change with maturation.

Since myelin contains far more saturated than polyunsaturated fatty acids, these studies provide indirect evidence linking the microsomal fatty acid-synthesizing system with the function of providing the long-chain fatty acids required for myelination.

The factors regulating fatty acid biosynthesis in the developing brain have not been examined up to now, but the endocrine system, in particular the thyroid, has been implicated in this process. In rats, thyroidectomized at birth, the growth rate of the perikaryon of brain is reduced, and both neurons and glia become more closely aggregated than normal. There is also a selective reduction in the length and branching of dendrites, and a progressive reduction is axodendritic connectivity [7]. The chemical correlates of these morphological changes include alterations in many variables of cerebral metabolism. Thyroid hormone stimulates amino acid incorporation into brain proteins of immature animals, both in vivo and in vitro, through one or more of the following mechanisms: enhancement of the transfer of soluble, RNA-bound amino acids to microsomal protein $[9,11,16,17]$; stimulation of RNA synthesis, particularly ribosomal RNA; increase in amino acid incorporation by newly synthesized ribosomes; and readjustment of the permeability barriers [18]. Simultaneously, the hormone influences the activity of a number of enzymes in immature rat brain, including succinic dehydrogenase [10], glutamic acid decarboxylase [3], and galactolipid sulfotransferase [19]. Thyroid hormone also affects the concentration of myelin components. In rats made hypothyroid at birth, cerebroside, sulfatide, and cholesterol concentrations are markedly reduced while the incorporation of ${ }^{35} \mathrm{SO}_{4}$ into sulfatides is decreased and slowed [19].

In the liver, fatty acid biosynthesis is reduced following thyroid therapy [8], in part as a consequence of a fall in NADH levels resulting from a reduction in hepatic glycogen concentration and diminished glycogenolysis.

Although other hormones, such as estradiol and cortisol, may also influence myelination, we undertook a study of the action of thyroid hormone on fatty acid biosynthesis in the mitochondrial and microsomal fractions of developing brain as an initial step to clarify some of the factors controlling fatty acid biosynthesis.

\section{Materials}

Acetyl-1-14C-CoA and malonyl-1, 3-14C-CoA [20], and the cofactors adenosine triphosphate (ATP), NADH, NADPH, creatine phosphate, and creatine phosphokinase [21] were obtained from commercial sources. Lipids and fatty acid standards were obtained from another laboratory [22], and Cab-O-Sil, PPO, and POPOP were obtained commercially [23].

\section{Methods}

Three or four immature rats of the Sprague-Dawley strain, age 3-20 days, and mature animals, age 2-4 months, were used in each experiment. Starting from birth, until their death, rats were injected daily with $3,5,3$ '-triiodo-L-thyronine $\left(T_{3}\right)$ intraperitoneally $(60$ $\mu \mathrm{g} / 100 \mathrm{~g}$ body weight dissolved in a solution of $0.01 \mathrm{~N}$ $\mathrm{NaOH}$ ). Control animals were injected with the same amount of $0.01 \mathrm{~N} \mathrm{NaOH}$. The last injection was administered approximately $2 \mathrm{hr}$ prior to killing. $\mathrm{Hy}$ pothyroidism was induced in newborn animals by daily subcutaneous injections of methimazole starting at birth [24].

Littermates for each age group were decapitated and brains were removed immediately and placed in a chilled sucrose $(0.25 \mathrm{~m})$ solution. All subsequent operations were carried out at a temperature of about $4^{\circ}$. Tissue homogenation, preparation of subcellular fractions, and protein determination were done as described previously $[1,2]$.

\section{Incubation Mixture}

The reaction mixture contained $100 \mathrm{~m} \mu$ moles acetyl-1-14 $\mathrm{C}-\mathrm{CoA}(8.5 \mu \mathrm{Ci} / \mu$ mole $)$, or $90 \mathrm{~m}_{\mu}$ moles malonylI , 3-14 C-CoA (9.4 $\mu \mathrm{Ci} / \mu$ mole), $16 \mu$ moles ATP, $3 \mu$ moles NADH, $3 \mu$ moles NADPH; $20 \mu$ moles $\mathrm{MgCl}_{2}, 20$ $\mu$ moles creatine phosphate, $0.25 \mathrm{mg}$ creatine phosphokinase, $60-100 \mu$ moles potassium phosphate buffer, $\mathrm{pH}$ 7.2, and $2.0-4.7 \mathrm{mg}$ mitochondrial or microsomal protein in a final volume of $1.0 \mathrm{ml}$. The average protein content used in the incubation mixtures was $2.85 \mathrm{mg}$ 
for the microsomal fraction, and $2.75 \mathrm{mg}$ for the mitochondrial fraction. The tubes were gently flushed with nitrogen, stoppered, and incubated at $37.8^{\circ}$ for $30 \mathrm{~min}$. Previous experiments indicated that incorporation of substrate into fatty acids was linear for about $30 \mathrm{~min}$, then decreased to $58 \%$ linearity at $1 \mathrm{hr}[1]$.

\section{Determination of Incorporation of Radioactivity into Fatty Acids}

At the end of the incubation period, the reaction mixture was saponified for $1 \mathrm{hr}$ at $95^{\circ}$ under nitrogen using an equal volume of $20 \%$ methanolic $\mathrm{KOH}$. The nonsaponifiable compounds were extracted with hexane, and the aqueous phase was acidified with $4 \mathrm{~N}$ $\mathrm{HCl}$; the fatty acids liberated were extracted with three successive portions of hexane. The combined extracts were concentrated to a known volume under a stream of nitrogen. An aliquot (usually $1 / 10$ ) was transferred to a counting vial and dried under nitrogen; $12-15 \mathrm{ml}$ of a scintillation mixture consisting of $0.5 \%$ 2,5-diphenyloxazole (PPO), and $0.03 \%$ 1,4-bis(2-(5phenyloxazolyl)benzene) (POPOP) in toluene were added. Radioactivity was counted in a liquid scintillation spectrometer [25]. Results were expressed as millimicromoles of ${ }^{14} \mathrm{C}$-labeled substrate incorporated into fatty acids per milligram of protein in the incubation mixture.

\section{Gas-Liquid Chromatography and Identification of Fatty Acids}

The hexane extract of the radioactive fatty acids was taken to dryness under a stream of nitrogen; fatty acid methyl esters were prepared by heating at $95^{\circ}$ for 5 min with $14 \%$ boron trifluoride in methanol [13] and purified by thin layer chromatography [5]. Gas-liquid chromatography was carried out in a gas chromatograph [26] with an argon detector. Diethylene glycol succinate on Gas-Chrom Z [22], 100-120 mesh, and methyl silicone (SE-30) were used as stationary phases. Radioactive fatty acid methyl esters were collected from the gas chromatograph using small filters [27] and the radioactivity was measured. Recovery was about $70-80 \%$ of applied radioactivity. Peaks were identified by chromatography with mixtures of fatty acid methyl ester standards.

\section{Separation of Fatty Acids by Thin Layer Chromatog- raphy}

An aliquot of the total fatty acid methyl esters was separated into saturated, mono- and polyunsaturated fatty acid esters by thin layer chromatography on Silica Gel G impregnated with $5 \%$ silver nitrate, using hexane-ether $(90: 10, v / v)$ as the developing solvent. Fatty acid esters were identified by reference to concurrently chromatographed standards. Areas corresponding to each group of fatty acid esters were scraped from the plate and placed into counting vials with 15 $\mathrm{ml}$ scintillation mixture $(0.5 \% \quad \mathrm{PPO}$ and $0.3 \%$ POPOP). Cab-O-Sil, $0.6 \mathrm{~g}$ [23], was added to each vial, together with 1-2 drops of glacial acetic acid, and the mixture was counted. Better than $95 \%$ of the radioactivity applied to the thin layer plate was recovered by this procedure.

\section{Results}

\section{Incorporation of Acetyl-1 ${ }^{14} \mathrm{C}-\mathrm{CoA}$ into Fatty Acids by Mitochondrial Fraction}

In both the $\mathrm{T}_{3}$-treated and control animals maximal incorporation of acetyl-CoA into fatty acids by mitochondria occurred at 15 days of age (Fig. 1). At 5-6 days of age the incorporation was greater in treated animals, but no significant difference could be observed in any other age group. Acetyl-CoA was incorporated into saturated, mono- and polyunsaturated fatty acids, with the greatest amount of radioactivity in both treated and control animals of all ages being found in the polyunsaturated fatty acid fraction. No significant change in the proportion of the various fatty acids occurred as a result of thyroid therapy.

Incorporation of Malonyl-1,3-14C-CoA into Fatty Acids by Microsomal Fraction

As noted previously for control animals [1], incorporation of malonyl-CoA into fatty acids by the microsomal fraction was maximal at 15 days of age in thyroidtreated rats. Thyroid stimulation was maximal at 5-6 days of age, with the incorporation increasing from $0.91 \pm 0.52 \mathrm{~m} \mu \mathrm{mole} / \mathrm{mg}$ protein to $2.25 \pm 0.39$ $\mathrm{m}_{\mu}$ moles $/ \mathrm{mg}$ protein $(P<0.01)$ (Table $\left.\mathrm{I}\right) . \mathrm{T}_{3}$-induced stimulation of precursor incorporation was not significant in 9- and 14- to 16-day-old animals. No stimulation was seen at 20 days or in adult animals (Fig. 2). Direct addition of $T_{3}$ to the in vitro system had no effect on total fatty acid biosynthesis.

When the pattern of fatty acids synthesized in control animals was compared with that of $T_{3}$-treated rats, it became evident that at days $5-6,8-9$, and 14-15 $T_{3}$ treatment induced a significant increase in the proportion of labeled malonyl-CoA incorporated into satu- 


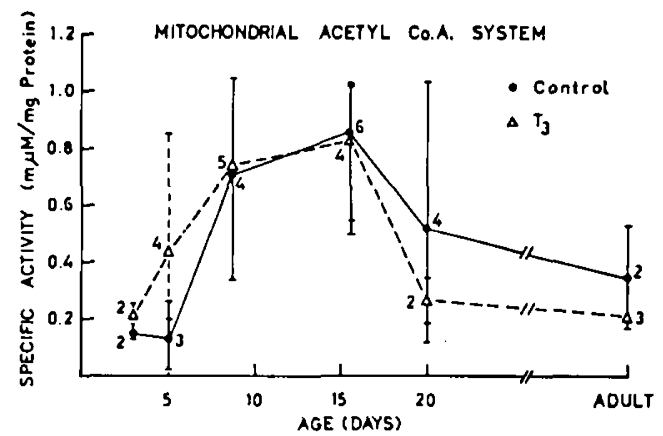

Fig. 1. In vitro incorporation of ${ }^{14} \mathrm{C}$-labeled acetyl-CoA into total fatty acids by rat brain mitochondria during development in thyroid-injected and control rats. Results are expressed in terms of millimicromoles of ${ }^{24} \mathrm{C}$-labeled substrate incorporated into fatty acids per milligram of mitochondrial protein in the incubation mixture. The complete system is described in Methods. Brackets indicate range of values; numbers under each figure point are the number of experiments.

Table $I$. Incorporation of malonyl-1, 3-14 $\mathrm{C}$-CoN into fatty acids by brain microsomes in thyroid-treated and control rats

\begin{tabular}{lccc}
\hline & \multirow{2}{*}{ Age, days } & \multicolumn{2}{c}{$\begin{array}{c}\text { Substrate incorporation, } \\
\text { m } \mu \text { mole/mg protein }\end{array}$} \\
\cline { 3 - 4 } & & Control & Thyroid \\
\hline Total fatty acids & 5 & 0.91 & 2.25 \\
$\quad$ Saturated & & 0.36 & 1.46 \\
Monounsaturated & & 0.02 & 0.19 \\
Polyunsaturated & & 0.52 & 0.55 \\
Total fatty acids & \multirow{2}{*}{$8-9$} & 1.99 & 2.24 \\
Saturated & & 0.68 & 1.39 \\
Monounsaturated & & 0.24 & 0.20 \\
Polyunsaturated & & 1.06 & 0.65 \\
& & & \\
Total fatty acids & $14-15$ & 3.97 & 4.52 \\
Saturated & & 2.27 & 3.48 \\
Monounsaturated & & 0.30 & 0.32 \\
Polyunsaturated & & 1.39 & 0.67 \\
\hline
\end{tabular}

rated fatty acids (Table II). (Respective $P$ values: $<0.01,<0.01$, and $<0.02$.)

Calculation of the above values, in terms of amounts of each type of fatty acid synthesized from labeled malonyl-CoA, showed that the previously noted significant increase in total fatty acid synthesis at 5-6 days of age was found to be due to an increased synthesis of saturated and monounsaturated fatty acids. At 9 and 14-16 days of age, increased synthesis of saturated fatty acids was compensated for by a reduction in the incorporation of precursor into polyunsaturated fatty acids (Table I). Gas-liquid chromatography of the saturated fatty acid fraction did not reveal any significant difference with respect to the distribution of radioactivity between thyroid-treated and control animals.
Incorporation of ${ }^{14} \mathrm{C}$-labeled Substrate into Fatty Acids by Brain Subcellular Particles in Hypothyroid Rats

In rats made hypothyroid at birth, incorporation of both malonyl-CoA by the microsomal fraction and acetyl-CoA by the mitochondrial fraction was markedly reduced (Table III).

\section{Discussion}

The importance of saturated and monounsaturated fatty acids in the formation and maintenance of myelin has been well recognized [15]. In liver and mature brain the microsomal system is predominantly con-

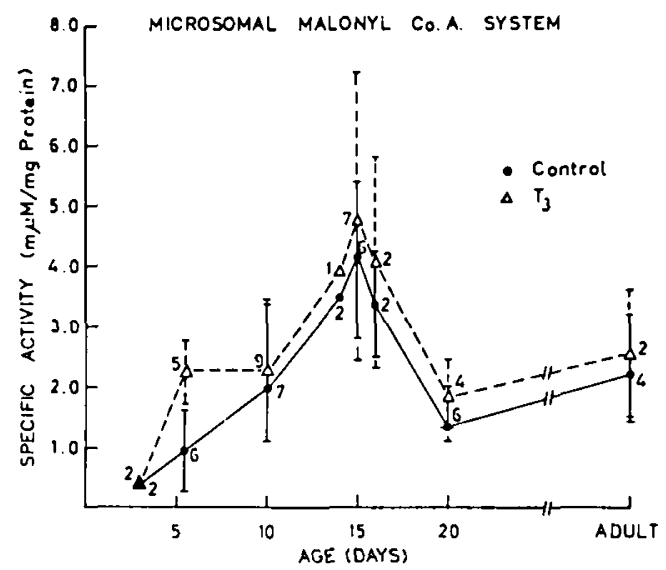

Fig. 2. In vitro incorporation of ${ }^{14} \mathrm{C}$-labeled malonyl-CoA into total fatty acids by rat brain microsomes during development in thyroid-injected and control rats. Results are expressed in terms of millimicromoles of ${ }^{14} \mathrm{C}$-labeled substrate incorporated into fatty acids per milligram of microsomal protein in the incubation mixture. The complete system is described in Methods. Brackets indicate range of values; numbers under each figure point are the number of experiments.

Table II. Incorporation of malonyl-1 , 3-14 $\mathrm{C}$-Co $\Lambda$ into fatty acids by brain microsomes in thyroid-treated and control rats ${ }^{1}$

\begin{tabular}{|c|c|c|c|c|}
\hline \multirow{2}{*}{$\begin{array}{l}\text { Age, } \\
\text { days }\end{array}$} & & \multicolumn{3}{|c|}{ Substrate incorporation, $\%$} \\
\hline & & Saturated & $\begin{array}{c}\text { Mono- } \\
\text { unsaturated }\end{array}$ & $\begin{array}{c}\text { Poly- } \\
\text { unsaturated }\end{array}$ \\
\hline \multirow[t]{2}{*}{$5-6$} & Control $(6)^{2}$ & $39.8 \pm 4.0^{2}$ & $2.6 \pm 1.1$ & $57.4 \pm 4.3$ \\
\hline & Thyroid (4) & $\begin{array}{c}65.0 \pm 6.3 \\
P<0.01\end{array}$ & $\begin{array}{c}8.6 \pm 5.4 \\
P=\end{array}$ & $\begin{array}{c}24.4 \pm 2.2 \\
P<0.01\end{array}$ \\
\hline \multirow[t]{2}{*}{$8-9$} & Control (3) & $34.4 \pm 1.6$ & $12.0 \pm 4.9$ & $53.4 \pm 3.7$ \\
\hline & Thyroid (6) & $\begin{array}{c}61.9 \pm 10.6 \\
P<0.01\end{array}$ & $\begin{array}{c}9.0 \pm 3.0 \\
P=\end{array}$ & $\begin{array}{c}29.0 \pm 10.8 \\
P<0.01\end{array}$ \\
\hline \multirow[t]{2}{*}{$14-15$} & Control (4) & $57.2 \pm 8.6$ & $7.6 \pm 1.9$ & $35.0 \pm 8.9$ \\
\hline & Thyroid (4) & $\begin{array}{c}77.1 \pm 5.7 \\
P<0.02\end{array}$ & $\begin{array}{c}7.1 \pm 1.4 \\
p\end{array}$ & $\begin{array}{c}14.4 \pm 5.3 \\
P<0.02\end{array}$ \\
\hline
\end{tabular}

1 Values are expressed as the mean of the percentage of total radioactivity incorporated into total fatty acids $\pm 1 \mathrm{sD}$.

2 Figures in brackets indicate number of experiments, each using three to four animals. 
Table III. Incorporation of radioactivity into total fatty acids by microsomal and mitochondrial fractions in normal and hypothyroid rats 1

\begin{tabular}{cccccc}
\hline \multirow{2}{*}{$\begin{array}{c}\text { Age, } \\
\text { days }\end{array}$} & \multicolumn{3}{c}{ Substrate incorporation, $m \mu$ moles/mg protein } \\
\cline { 2 - 3 } \cline { 5 - 6 } \cline { 5 - 6 } & \multicolumn{2}{c}{ Mitochondria } & \multicolumn{2}{c}{ Microsomes } \\
\cline { 2 - 3 } \cline { 5 - 6 } & Normal & Hypothyroid & & Normal & Hypothyroid \\
\hline 6 & 0.38 & 0.10 & & 1.41 & 0.17 \\
15 & 0.35 & 0.14 & & 2.90 & 1.00 \\
& 0.79 & 0.88 & & 3.70 & 1.91 \\
\hline
\end{tabular}

${ }^{1}$ Results are expressed in millimicromoles of ${ }^{14} \mathrm{C}$-labeled substrate: acetyl-CoA for mitochondrial fraction, malonyl-CoA for microsomal fraction, incorporated into fatty acids per milligram protein in the incubation mixture. The complete system contained the components as described in Methods. The reaction mixture was incubated for $30 \mathrm{~min}$.

cerned with chain elongation of polyunsaturated fatty acids. By contrast, the mitochondrial system of brain at all ages synthesizes a variety of saturated, monounsaturated, and polyunsaturated fatty acids and has the potential ability to form nervonic and lignoceric acids by chain elongation [4]. In our study, stimulation of fatty acid biosynthesis by thyroid hormone was limited to the formation of saturated fatty acids by the microsomal system. At 5 days of age, the increase in the synthesis of saturated fatty acids was reflected by increased malonyl-CoA incorporation into total fatty acids, but in older animals the formation of polyunsaturated fatty acids was reduced sufficiently so that total fatty acid synthesis was only slightly augmented. This phenomenon may have been the result of incubating conditions where the enzyme concentration, i.e., the amount of microsomal protein, was rate-limiting.

In hypothyroid rats, fatty acid chain elongation was reduced in both mitochondrial and microsomal fractions, although the microsomal fraction again appeared to be more sensitive to hormonal alterations.

On the basis of clinical and histologic studies, it has been known for many years that thyroid accelerates brain development, although the mechanism of its action has not been explained. Myant and Cole [14] found no specific stimulatory effect of thyroid on the uptake of ${ }^{32} \mathrm{P}$ and ${ }^{14} \mathrm{C}$ by brain slices and concluded that thyroid only accelerates brain maturation by stimulation of protein synthesis. Walravens and Chase [19] found that thyroidectomy reduced the concentration of cerebrosides and sulfatides in brain, but they did not attempt to localize further the site of thyroid action.

Although a variety of enzyme systems, most of them located in the microsomal fraction [12], are involved in the biosynthesis of glycolipids, a defect in the formation of long-chain fatty acids by the elongation of palmitate as is suggested by our studies would, of itself, be sufficient to account for delayed or defective myelination.

At present we are unable to state how thyroid hormone affects fatty acid biosynthesis, and in particular specifically stimulates the formation of saturated fatty acids. On the basis of previously reported rate studies [1], we have suggested that the microsomal fraction possesses two distinct mechanisms for fatty acid biosynthesis, one for the production of saturated, the other for production of polyunsaturated fatty acids. The former becomes more active during maturation and is also stimulated by thyroid hormone. Very little is known about the enzymes involved in the chain elongation of fatty acids in mammalian tissues and the site of the rate-limiting enzyme; the nature of the thyroid stimulation must await solubilization and fractionation of the microsomal chain elongation system.

\section{Summary}

The effect of thyroid hormone on fatty acid biosynthesis by rat brain was studied. Administration of thyroid to immature animals increased the incorporation of malonyl-CoA into saturated fatty acids. In the 5- to 6-day-old animal thyroid also enhanced total fatty acid synthesis. In animals made hypothyroid at birth, fatty acid biosynthesis was reduced, with the effect being most evident in the microsomal system.

\section{References and Notes}

1. Aeberhard, E., Grippo, J., And Menkes, J. H.: Fatty acid biosynthesis in the developing brain. Pediat. Res., 3: 590 (1969).

2. Aeberinard, E., ANd Menkes, J. H.: Biosynthesis of long chain fatty acids by subcellular particles of mature brain. J. Biol. Chem., 243: 3834 (1968).

3. Balazs, R., Kovacs, S., Teichugüber, P., Cocks, W. A., and EAYRS, J. T.: Biochemical effects of thyroid deficiency on the developing brain. J. Neurochem., 15: 1335 (1968).

4. BoONE, S. C., AND WAKIL, S. J.: In vitro synthesis of lignoceric and nervonic acids in mammalian liver and brain. Biochemistry, 9: 1470 (1970).

5. Bowyer, D. E., Leat, IV. M. F., Howard, A. N., ANd Gresham, G. A.: The determination of the fatty acid composition of serum lipids separated by thin-layer chromatography; and a comparison with column chromatography. Biochim. Biophys. Acta, 70: 423 (1963).

6. BrADY, R. O.: Biosynthesis of fatty acids. II. Studies with enzymes obtained from brain. J. Biol. Chem., 235: 3099 (1960).

7. EAYRS, J. T.: Thyroid and central nervous development. In: Scientific Basis of Medicine, Annual Reviews, University of London, p. 317 (Athlone Press, London, 1966). 
8. Fletcher, K., and Myant, N. B.: Partial reversal of the effects of thyroxine on lipid synthesis in rat liver by the addition of cofactors in vitro. J. Physiol., 157: 542 (1961).

9. Gelber, S., Campbell, P. L., Deibler, G. E., ANd Sokoloff, L.: Effects of $\mathrm{L}$-thyroxine on amino acid incorporation into protein in mature and immature rat brain. J. Neurochem., 11: 221 (1964).

10. Hamburgi, M., and Flexner, L. B.: Biochemical and physiological differentiation during morphogenesis: XXI: Effect of hypothyroidism and hormone therapy on enzyme activities of the developing central cortex of rat. J. Neurochem., 1: 279 (1957).

11. KLEE, C. B., AND SokolofF, L.: Mitochondrial differences in mature and immature brain. Influence on rate of amino acid incorporation into protein and responses to thyroxine. J. Neurochem., 11: 709 (1964).

12. Morell, P., and Radin, N. S.: Specificity in ceramide biosynthesis from long chain bases and various fatty acid coenzyme A's by brain microsomes. J. Biol. Chem., 245: 342 (1970).

13. Morrison, W. R., AND SMITH, L. M.: Preparation of fatty acid methyl esters and dimethyl acetals from lipid with boron fluoride-methanol. J. Lipid Res., 5: 600 (1964).

14. Myant, N. B., AND Cole, L. A.: Effect of thyroxine on the deposition of phospholipids in the brain in vivo and on the synthesis of phospholipids by brain slices. J. Neurochem., 13: 1299 (1966).

15. O'BRIEN, J. S.: Stability of the myelin membrane. Science, 147: 1099 (1965).

16. Sokoloff, L.: Action of thyroid hormones and cerebral development. Amer. J. Dis. Child., 114: 498 (1967).

17. Sokoloff, L., Kaufman, S., Campbell, P. L., Francis, C. M.,
ANd Gelboin, H. V.: Thyroxine stimulation of amino acid incorporation into protein: Localization of stimulated step. J. Biol. Chem., 238: 1432 (1963).

18. TAte, J. R.: Hormonal regulation of growth and protein synthesis. Nature, 219: 331 (1968).

19. Whlravens, P., and Chase, H. P.: Influence of thyroid on formation of myelin lipids. J. Neurochem., 16: 1477 (1969).

20. New England Nuclear Corporation, Boston, Mass.

21. Sigma Chemical Company, St. Louis, Mo.

22. Applied Science Laboratories, State College, Pa.

23. Cab-O-Sil; PPO (2,5-diphenyl oxazole) and POPOP (1,4-bis(2(5-phenyloxazolyl))-benzene) were obtained from Packard Company, La Grange, Ill.

24. Methimazol, 1-methyl-2-mercaptoimidazole, kindly provided by Dr. J. M. McGuire, Lilly Research Laboratories, Indianapolis, Incl.; $5 \mathrm{mg} / 100 \mathrm{~g}$ body weight were administered, dissolved in a $0.9 \%(\mathrm{w} / \mathrm{v}) \mathrm{NaCl}$ solution.

25. Tri-Carb, Packard Instrument Company, Downers Grove, Ill.

26. Model 10, Barber-Colman, Chromatography Division of $\mathrm{Nu}$ clear-Chicago, Des Plaines, Ill.

27. Estron Filterrods (type F D-340), Eastman Chemical Products, Kingsport, Tenn.

28. Prescnted in part at the 30th Annual Meeting of the Society for Pediatric Research, Atlantic City, N. J., May, 1970.

29. Supported by National Institutes of Health Grant no. NB 06938 and by the National Genctics Foundation.

30. Requests for reprints should be addressed to: John $H$. Menkes, M.D., Division of Pediatric Neurology, UCLA School of Medicine, The Center for the Health Sciences, Los Angeles, Calif. 90024 (USA).

31. Accepted for publication November 5, 1970. 